\title{
O despertar de uma nova gestação após o nascimento de um bebê malformado
}

\author{
The awakening of a new pregnancy after the birth of a malformed baby \\ El despertar de un nuevo embarazo tras el nacimiento de un bebé malformado
}

\author{
Ivia Santos de Carvalho' ${ }^{\circledR}$; Cristiane Vanessa da Silva' ${ }^{\circledR}$; \\ Adriana Peixoto da Silva' @ ; Fernanda Rodrigues Chaves Morais ${ }^{\circledR}$
}

\begin{abstract}
'Fundação Oswaldo Cruz, Rio de Janeiro, RJ, Brasil
RESUMO

Objetivo: compreender os sentimentos que envolvem uma nova gravidez após o nascimento de um bebê malformado. Método: estudo descritivo e qualitativo, apoiado no método narrativa de vida, com dez mulheres que decidiram engravidar após a experiência prévia de malformação congênita. Os dados foram coletados por meio de entrevistas no primeiro semestre de 2019, em uma maternidade do Rio de Janeiro, e submetidos à técnica de análise temática, com a devida aprovação pelo Comitê de Ética em Pesquisa. Resultados: os principais sentimentos externados foram medo, desespero e rejeição, mas o desejo de maternar, e não somente gestar e parir, impulsionou as participantes a engravidar novamente. Conclusão: o planejamento reprodutivo é fundamental para desmistificar sentimentos negativos relacionados à malformação fetal e trazer boas expectativas para nova gestação.

Descritores: Anormalidades Congênitas; Mães; Gravidez.
\end{abstract}

\begin{abstract}
Objective: to understand the feelings surrounding a new pregnancy after the birth of a malformed baby. Method: in this descriptive, qualitative study, supported by the life narrative method, with 10 women who decided to conceive after a previous experience of congenital malformation, data were collected through interviews in the first half of 2019, at a maternity hospital in Rio de Janeiro, and subjected to the thematic analysis technique, after due approval by the research ethics committee. Results: the main feelings expressed were fear, despair, and rejection, but the desire to mother, and not just to gestate and give birth, drove the participants to get pregnant again. Conclusion: reproductive planning is essential to demystify negative feelings relating to fetal malformation and raise good expectations for a new pregnancy.
\end{abstract}

Descriptors: Congenital Abnormalities; Mothers; Pregnancy.

\section{RESUMEN}

Objetivo: comprender los sentimientos que involucran un nuevo embarazo tras el nacimiento de un bebé con malformaciones. Método: estudio descriptivo y cualitativo, basado en el método de narrativa de vida, con 10 mujeres que decidieron quedar embarazadas luego de una experiencia previa de malformación congénita. Se recolectaron los datos a través de entrevistas en el primer semestre de 2019, en una maternidad en Río de Janeiro, y luego se sometieron a la técnica de análisis temático con la debida aprobación por parte del Comité de Ética en Investigación. Resultados: Los principales sentimientos expresados fueron el miedo, la desesperación y el rechazo, pero el deseo de maternar, y no solo de quedar embarazada y dar a luz, empujó a las participantes a volver a quedar embarazadas. Conclusión: La planificación reproductiva es fundamental para desmitificar los sentimientos negativos relacionados con la malformación fetal y generar buenas expectativas para un nuevo embarazo.

Descriptores: Anomalias Congénitas; Madres; Embarazo.

\section{INTRODUÇÃO}

A gestação é um fenômeno único e complexo na vida da mulher. Trata-se, portanto, de um momento no qual o corpo se adapta para abrigar o feto em desenvolvimento passando por intensas mudanças hormonais e emocionais que repercutem sobre os aspectos físicos, psicológicos e biológicos. A gestante e o feto passam por experiências únicas e, mesmo para aquelas que já experimentaram a gestação mais de uma vez, o processo é sempre uma novidade por conta das incertezas, dos medos e da ansiedade que parecem sempre se renovar, especialmente se houve intercorrências na gravidez anterior ${ }^{1,2}$.

A maioria dos casais sonha com o nascimento de um filho perfeito, idealizando um evento socialmente esperado. Porém, diante da experiência prévia de uma malformação fetal, pode ocorrer uma descontinuidade relacionada à construção imagética de bebê perfeito, fazendo emergir sentimentos negativos associados à possibilidade de recorrência da malformação ${ }^{3}$.

Diante da confirmação do diagnóstico, há um confronto entre o filho imaginário e o real, sendo que a adaptação ao bebê com malformação congênita é um processo gradual de aceitação e compreensão sobre o novo fato, com repercussões intensas no âmbito familiar ${ }^{3,4}$. 
Segundo dados do Instituto Brasileiro de Geografia e Estatística (IBGE), o número de nascimentos no Brasil foi 2.793.935 em 2016, correspondendo a uma taxa de nascimento de 14,3 nascimentos/1000 habitantes ${ }^{5,6}$. Dentre as anomalias congênitas identificadas no nascimento e, devidamente registradas, destacam-se as relacionadas ao aparelho osteomuscular, com 6.448 casos, seguidas daquelas que afetam o Sistema Nervoso Central, representando 4.085 casos, além das classificadas como outras malformações congênitas, totalizando 3.257 casos $^{6}$.

$\mathrm{Na}$ década de 1980, as malformações ocupavam a quinta, e última, posição entre as principais causas de mortalidade infantil, o que correspondia a $5 \%$ do total. Atualmente, passaram a ocupar o segundo lugar, respondendo por $13 \%$ dos óbitos de menores de $1 \mathrm{ano}^{4}$.

Considerando que as crianças com malformações congênitas requerem cuidados de saúde e que suas famílias, normalmente, vivenciam situações de crise em função do desgaste emocional e da necessidade de suporte financeiro ${ }^{4}$, emergiram os seguintes questionamentos: Como foi para a mulher engravidar após o nascimento de um bebê malformado? Quais sentimentos estiveram presentes nessa nova gravidez? Para responder a estas questões, o presente artigo tem como objetivo compreender os sentimentos que envolvem uma nova gravidez após o nascimento de um bebê malformado.

\section{MÉTODO}

Estudo descritivo com abordagem qualitativa, apoiado no método narrativa de vida. A opção por este delineamento metodológico permitiu o conhecimento do objeto em profundidade, ao trabalhar com a subjetividade, e de seus valores em meio a um universo de significados e sentimentos que levaram as mulheres, com a experiência prévia de um bebê malformado, a decidirem por engravidar novamente, considerando e compreendendo o que foi mais relevante na experiência de cada entrevistada7.

A amostra por conveniência foi definida tendo como critério de inclusão: ser maior de 18 anos e ter gestado anteriormente um bebê com malformação. Foram excluídas as mulheres nas seguintes situações: internação em trabalho de parto ou no pós-parto imediato, bem como as portadoras de déficit cognitivo ou qualquer comprometimento mental.

A captação das participantes ocorreu de modo privativo, à beira do leito, durante a internação na enfermaria de gestante e alojamento conjunto de uma maternidade referência para risco fetal, situada no município do Rio de Janeiro. As entrevistas foram realizadas pela pesquisadora principal, nos dias em que a mesma estava de plantão, responsabilizando-se pelo cuidado direto à essas mulheres. Essa proximidade permitiu um período de ambientação, propiciando a criação de vínculo e uma atmosfera de confiança para que as mesmas pudessem expor seus pensamentos durante a entrevista.

A coleta de dados aconteceu no período de janeiro a maio de 2019 , sendo realizado um teste piloto, não contabilizado na análise. Ressalta-se que não houve recusas ou necessidade de repetir as entrevistas, alcançando um total de dez participantes, das quais cinco eram gestantes e cinco eram puérperas.

As entrevistas narrativas abertas partiram da questão disparadora "Conte como foi engravidar após ter um bebê malformado", foram gravadas em MP4 e tiveram duração média de 30 minutos. As mesmas foram transcritas na íntegra, codificadas com a letra $\mathrm{M}$, de mulher, seguida do número de ordem da realização.

A técnica de análise temática foi processada após leitura exaustiva das narrativas, com destaque dos trechos que se aproximavam aos objetivos do estudo e extração dos principais temas que foram categorizados e compuseram o corpus da análise.

A pesquisa foi aprovada pelo Comitê de Ética em Pesquisa e todos os preceitos éticos foram resguardados e as participantes assinaram um Termo de Consentimento Livre e Esclarecido, com o subsequente recebimento, pela participante, de uma cópia do mesmo.

\section{RESULTADOS E DISCUSSÃO}

Em relação à caracterização das participantes do estudo, cinco se autodeclararam brancas e cinco pardas, com idade entre 24 e 38 anos. A maioria é solteira, evangélica e com apenas um filho vivo. No tocante à escolaridade, quatro possuem ensino fundamental, quatro completaram o ensino médio, duas concluíram o ensino superior. Sobre a renda familiar, a maioria declarou receber menos de dois salários-mínimos.

\section{Sentimentos de gestar após partos de malformados}

O despertar de uma nova gravidez após o nascimento de um bebê malformado se ancorou no desejo das mulheres de exercerem a maternagem. Para elas, o sonho de ser mãe não era somente gestar e parir, mas envolvia cuidado, amamentação e a realização como mãe. 
[...] ]eu queria saber como era ter esse sentimento de mãe. Eu queria saber o que era ser mãe [...] amar como mãe [...] Eu queria saber como era amamentar, cuidar, amar, o sentimento era esse! Eu sempre gostei de criança! (M9).

[...] ]era o sonho de ser mãe! Queria muito, mas como não conseguia... Quando eu soube que podia ser, eu fui atrás, mesmo que viesse uma criança especial, eu ia amar meu filho da mesma forma! O amor é a mesma coisa, quando a gente quer muito um sonho, consegue realizar.... Me sinto realizada de ter ele, tem hora que eu nem acredito ainda que é meu! (M2).

O pensamento Winnicottiano trabalha a maternagem como uma forma da mãe cuidar de seu bebê de maneira boa e protetora, com vistas ao atendimento das necessidades fisiológicas e ao investimento de desejo, amor e aconchego ${ }^{8}$. Este estado de preocupação primária emerge ao final da gestação, sendo para muitos um extinto natural que direciona parte significativa da atenção com sua própria existência, buscando dedicar-se, exclusivamente, ao filho para, por meio da criança, satisfazê-la com um conjunto de cuidados ${ }^{9}$.

A preocupação materna primária é a capacidade da mulher se envolver de forma intensa com as questões da maternidade, dedicando-se, inteiramente, a essa experiência ${ }^{8}$. Trata-se de um processo espontâneo que demanda atenção e acolhimento, para que a mulher exerça a função materna de modo favorável ao vínculo em construção, sobretudo em situações especiais como as malformações congênitas ${ }^{8}$.

A maternagem sempre é uma escolha por cuidar e dedicar-se com amor ao novo ser, e é este sentimento, esta devoção, este carinho, que algumas entrevistadas relataram sentir a necessidade de experimentar ${ }^{9}$.

Foi a vontade de maternar que se sobrepôs ao receio de tentar novamente, ao medo de novamente vivenciar uma morte neonatal ou o nascimento de um bebê com cuidados especiais. A busca pela maternidade completa impulsionou o despertar de um recomeço, embora esse desejo estivesse velado para maioria das participantes que relataram não querer engravidar em um momento próximo.

\section{[...] nenhum dos dois foi planejado. (M7).}

[...] a doutora falou para eu fazer o planejamento [reprodutivo]. Acabou que eu não fiz, depois de um ano eu fui lá e engravidei. (M4).

Na busca pela maternidade, ansiedades, medos, receios e preocupações são sentimentos comuns entre gestantes, mas potencializados diante de mulheres com vivência prévia de malformação congênita. A ansiedade é um estado emocional que tem componentes fisiológicos e psicológicos, abrangendo sensações de medo e insegurança associados ao pensamento pessimista de catástrofe ou incompetência pessoal ${ }^{10}$.

Toda a vez, toda a ultra [ultrassonografia], eu ficava me tremendo, mas o corpo todo! Sistema nervoso, mas tremia demais! (M9).

Eu estava muito ansiosa para fazer a translucência nucal! Até chegar a morfológica, eu... Mas pelos exames daqui que a gente fez, já me deixou mais tranquila porque a outra [se refere à gestação anterior] desde o início da transluscência já tinha dado alguma coisa...(M5)

Foi observado no estudo maiores níveis de estresse e sintomas psicológicos entre mulheres que receberam o diagnóstico de malformação antes do nascimento, ou seja, no período gestacional ${ }^{10}$. Os elevados índices de desinformação sobre a saúde do feto e as dificuldades maternas de elaborar e lidar com as mudanças inerentes ao período gestacional e à malformação infantil, interferem na saúde mental e favorecem estados de estresse, ansiedade e depressão. Embora a maioria não tenha planejado a gravidez, percebe-se que as mulheres nutrem um desejo por engravidar com o desfecho de um bebê saudável:

Não queria engravidar, mas foi rápido! Eu... adorei! [...] Tomei um susto! [...] no fundo, no fundo, eu queria engravidar novamente, porque eu tinha acabado de perder [...] (M10).

Eu estava tão ansiosa para ser mãe de novo, mas estava com medo de tentar porque foi muito complicado para gente... Saber que seu filho está ali, e não está ao mesmo tempo [...] (M2).

Os depoimentos mostram que não há adesão ao planejamento reprodutivo e apesar do medo de tentar uma nova gestação, as mulheres desejam engravidar novamente. Essa falha do planejamento reprodutivo, em acolher e atender as demandas específicas de mulheres com gestações prévias de malformados, gera inseguranças diante de uma nova gravidez:

Foi bom, mas ao mesmo tempo com medo. Só quem passa pela dor de perder um filho sabe como é... Medo que aconteça de novo! Eu vou vivendo um dia de cada vez, uma semana após a outra [...] (M1).

Sempre tive medo. Toda a gestação eu tinha medo! Eu engravidava e aí sempre perdia [...] Eu sempre tive medo de me apegar e acontecer a mesma coisa. Então, eu não curti minha gravidez! Ele, eu não curti! Eu tinha medo! (M9)

No início, eu tinha medo de comprar roupinha, de botar expectativa, de não dar certo [...] (M2). 
Apesar da capacidade adaptativa do ser humano, o medo relacionado à experiência prévia de um bebê malformado é um sentimento que culmina em um estado de fragilidade emocional diante do encontro com algo desconhecido e da possibilidade de recorrência em uma nova gestação ${ }^{11}$.

Entre gestantes de bebês com malformação congênita, percebe-se que o medo de perder o feto interfere no vínculo $^{12}$. Trata-se de um mecanismo de defesa comum diante da comunicação de notícias desagradáveis, que se caracteriza por uma interrupção abrupta no processo psíquico normal da gestação, fazendo com que muitas mulheres deixem o envolvimento em suspenso, evitando-se ações comuns de gestantes, como acariciar a barriga e preparar o enxoval, repercutindo negativamente sobre as relações familiares.

Para a maioria das participantes deste estudo, o medo esteve presente desde a descoberta da nova gestação até a realização da ultrassonografia obstétrica morfológica, por volta de 24 e 28 semanas, quando é possível visualizar o feto com melhor resolução. Por outro lado, mesmo após este exame diagnóstico, algumas mulheres relataram que este sentimento perdurou até o momento do nascimento, ou seja, no qual o contato visual e a constatação de boa vitalidade do recém-nascido sem malformações materializaram a tão desejada maternidade saudável.

[...] minha preocupação... Eu precisava ver ele! Ele na minha barriga, me trazia uma ansiedade muito grande!

[...] Aquilo me dava uma agonia muito grande [...] eu perguntava sempre no pré-natal: "Não vai fazer ultra?

[...] Preciso saber como essa criança está!" (M3)

A primeira morfológica, o médico falou que estava tudo certinho, perfeito, eu falei: "Nossa! Não estou acreditando que deu tudo certo! [...] Foi só felicidade! A partir disso, eu comecei a curtir a gravidez! (M9).

Tanto na ocasião da ultrassonografia durante a gestação quanto no nascimento, a identificação de intercorrências e a comunicação de más notícias não são situações para as quais a família está preparada para receber. Estes momentos podem suscitar traumas e desorganizações psicológicas, especialmente diante de malformação ou morte fetal ${ }^{13}$.

Outro sentimento que emana da descoberta de uma nova gestação após o nascimento de um bebê malformado é o desespero:

[...] eu acho que eu não estava preparada porque quando você está grávida, você fica muito sensível, então, tudo desespera. O medo do preconceito das pessoas, de como lidar com uma criança especial... Era muito difícil para mim! (M2).

[...] entrei em desespero! Porque ela faz acompanhamento médico [primeira filha]! Ter outro bebê? (M4)

Associado ao medo de que o novo ser tenha a mesma malformação do filho anterior, o desespero agrega o sentido de sobrecarga de trabalho, em meio a condição hormonal própria da gestação, com o receio de julgamentos e de uma possível cobrança social em função da nova gestação. Compartilhar a notícia da gravidez, nem sempre, é sinônimo de garantia de apoio. Muitas vezes, as mulheres se confrontam com manifestações de curiosidade e abordagens pouco respeitosas por parte de amigos e conhecidos. A despersonalização da mulher neste contexto e o foco voltado para a possibilidade de malformação do bebê podem ser elementos motivadores para que as gestantes redefinam a sua ação e adotem o silêncio como estratégia de proteção ${ }^{14}$.

A reação dos pais e o grau de apego ao recém-nascido, depende, em parte, do tipo de malformação: se é visível, se é passível de correção, se afeta o sistema nervoso central ou a genitália ou se é familiar. Tais características pressupõem os problemas futuros que enfrentarão, porém, independente do prognóstico da malformação fetal e da aparência da criança, as gestantes apresentaram alto nível de apego com seus fetos ${ }^{15}$.

[...] teve Arnold chiari tipo II, mas ele não aparenta ter essa malformação. Graças a Deus! Mas ele corrigiu a mielo [mielomeningocele] e a hidrocefalia. (M7)

[...] realmente tinha um pouco disso [...] Medo de descobrir alguma coisa no bebê, como outras doenças a mais! Síndrome de Down, outras coisas... Vindo ou não com algum probleminha [...] porque a preocupação também era vir com Síndrome de Down. (M8).

A localização das anormalidades apresentadas pelo recém-nascido tem influência direta no grau de ansiedade dos pais no tocante à preocupação com o futuro da criança. Na realidade, a menor anormalidade localizada na cabeça do neonato tem uma repercussão maior quanto à preocupação dos pais se comparada a um transtorno em qualquer outra parte do corpo ${ }^{16}$. Talvez esta explicação se justifique pela concepção de que o rosto caracteriza a parte mais expressiva do corpo.

[...] foi difícil nos primeiros dias para mim porque eu já tenho dois filhos e eles são normais, não têm nenhuma deficiência física, e essa ela teve [...] Agora, eu estou me acostumando... Ela faz tratamento. Eu a trato do mesmo jeito que os outros dois. (M10).

[...] Era intenção chegar esse dia... Bater a ultra morfológica para ver esse meu bebê! Não veio com a deficiência, com a má formação, como o irmão dele de 4 anos que veio com uma deficiência física. Depois que eu fiz a ultra morfológica, me deu um alívio, uma tranquilidade! (M6). 
[...] Só estava esperando ela chegar. Chegou no final que eu queria! Estava doida para ver o rosto dela! Para ver como é que ela ia nascer!(M7).

Ao gerar um filho com malformação, muitos pais se sentem culpados pelo desfecho e o interpretam como uma exposição social de seus erros e decisões. Tal percepção acentua sentimentos de impotência, angústia e fracasso ${ }^{3}$. Por outro lado, apesar da sensação de frustração, as mulheres querem viver o sonho de ser mãe com o nascimento de um bebê saudável.

Este desejo é compreendido como o futuro da linhagem parental, que emerge quando uma gravidez anterior gerou um bebê malformado e a vontade de gestar novamente permanece latente, como um mecanismo compensatório do desfecho prévio que é vivenciado de forma velada ${ }^{13}$. Nestes casos, diante da confirmação de uma nova gestação, o medo é um sentimento muito presente que pode ser transformado em felicidade, por meio de exames que demonstrem a normalidade fetal, ou desencadear a rejeição.

Com impactos importantes sobre a formação de vínculo dos pais com a nova criança, este processo de rejeição é comum, sobretudo entre mulheres desamparadas e sobrecarregadas em função das demandas relativas a outros filhos saudáveis ou filhos vivos com alguma malformação, os quais carecem de um acompanhamento de saúde recorrente.

$\mathrm{Na}$ atualidade, ainda nos deparamos com as desigualdades de gênero, que ditam o estereótipo de que é responsabilidade feminina o cuidado com os filhos, em especial das crianças com necessidades de saúde diferenciadas. Embora muitas mulheres exerçam trabalho remunerado, também cabe à elas o cuidado com o lar e com a prole, gerando uma rotina exaustiva e o sentimento de desamparo ${ }^{14}$.

[...] eu não queria mais filho de jeito nenhum! Não queria mais trabalho porque ela [filha anterior] já me dá um trabalho.......] Ela [filha anterior] é uma criança que tem que ficar 24 horas de olho. Imagina com duas crianças!! (M6)

[...] eu pensava: "Essa criança vai vir com limitação!" O pai dela [primeiro parceiro] não a aceita [filha anterior com malformação]. Agora, ele [parceiro atual] também não vai aceitar o filho [se vier com malformação]... Eu vou criar dois filhos especiais! [...] Eu entrei em depressão! (M3).

Observa-se que o cuidado de crianças com malformação é essencialmente feminino, desenvolvido pela própria mãe ou, quando a mesma possui vínculo empregatício, por outra mulher contratada para assumir a responsabilidade. Esta configuração apresenta traços da divisão sexual do trabalho e revelam desigualdades de gênero, frente à ausência ou pouca participação e envolvimento do homem neste processo ${ }^{17}$.

Além destas questões, é importante destacar o sentimento de culpa, manifestado pela própria mulher ou por meio do discurso masculino de culpabilização da mãe pela malformação:

[...] eu achei que a culpa era minha! Alguma coisa, [...] Então, eu fiquei muito com isso na cabeça [...] (M5).

[...] ele colocou na cabeça que minha filha tinha síndrome por minha causa! Porque a síndrome dela, a maior parte genética, vem da carga genética da mãe. [...] Só que eu já tinha feito o exame! [...] E descobri que eu não tenho. Foi por mutação! Foi de um em um milhão e ela nasceu! (M2).

De um modo geral, na busca das origens da malformação, as mulheres procuram em si mesmas uma justificativa ou explicação para o aparecimento do problema. A nova gestação, além de não convergir com os sonhos iniciais, renova os traumas e os descontentamentos prévios experimentados com o diagnóstico de malformação na gestação anterior ${ }^{12}$.

Assim, é comum os pais se sentirem culpados e responsáveis por essa situação, sendo que o abalo psíquico de ter um filho com deficiência pode afetar a capacidade feminina de maternar. Há, ainda, o sentimento materno de culpa que advém da ideia de permitir o nascimento de um filho com malformação congênita, como se a mesma tivesse controle sobre a situação ${ }^{13}$.

A culpabilização diante do ocorrido se dá por uma autocobrança, assim como, na evidente relação com o homem, uma vez que ela "carrega o bebê" elevando o seu status de maior propensão em se considerar responsável pelo desfecho da gestação ${ }^{18}$.

Cabe ponderar que os sentimentos vivenciados pelas participantes poderiam ser amenizados por meio do acesso aos serviços de saúde sexual e reprodutiva, baseados na humanização da assistência e nos direitos das mulheres de decidirem, ou não, por uma nova gestação após a vivência de uma malformação congênita. Engravidar não ao acaso, mas por escolha e com acompanhamento profissional qualificado para apoiá-las na vivência segura da maternidade e no desenvolvimento da maternagem com plenitude.

\section{Limitações do estudo}

Destaca-se como limitação do estudo o quantitativo da amostra, bem como sua regionalização, os quais não permite que os dados sejam generalizados. 


\section{CONCLUSÃO}

Os sentimentos que envolveram uma nova gravidez após o nascimento de um bebê malformado foram principalmente o medo, o desespero, a culpa e a rejeição. Ainda que o discurso das mulheres expresse o não desejo de uma nova gestação, as mesmas não adotam medidas protetivas para tal, visto que a vontade de vivenciar a gravidez e o nascimento de um filho saudável, bem como de desenvolver a maternagem permanecem latentes, apesar da experiência prévia com a malformação congênita e da possibilidade de sua recorrência.

O acolhimento das demandas de mulheres com gestação prévia de malformação ainda é um desafio a ser alcançado pelo planejamento reprodutivo, especialmente, em unidades de referência que ofertam serviços especializados. Orientação e informação são direitos fundamentais para garantir a saúde sexual e reprodutiva, com a concepção e a anticoncepção conscientes, pautadas na escolha do casal e no reconhecimento de suas especificidades.

Faz-se necessário novos estudos que explorem sentimentos e perspectivas de mulheres com gestação prévia de fetos malformados, a fim de visibilizar as necessidades deste grupo e, assim, impulsionar mudanças no planejamento reprodutivo sob a ótica das diversidades femininas.

\section{REFERÊNCIAS}

1. Nunes TS, Abrahão AR. Maternal repercussions of fetal anomaly pre-natal diagnosis. Acta paul. enferm. [Internet]. 2016 [cited 2021 Apr 11]; 29(5):565-72. DOI: https://doi.org/10.1590/1982-0194201600078.

2. Silva MAM, Marques FM, Brito MCC, Viana RS, Mesquita ALM, Silva ASR. et al. Operative group of primigravidae: a health promotion strategy. Rev. Bras. Promoç. Saúde. [Internet]. 2018 [cited 2019 Nov 29]; 31(1):1-11. DOI: https://doi.org/10.5020/18061230.2018.6406.

3. Machado MEC. Couples that receive a prenatal diagnosis of fetal malformation: a thought about the role of Hospital Psychologists. Rev. SBPH. 2012 [cited 2020 Nov 21]; 15(2):85-95. Available from: http://pepsic.bvsalud.org/scielo.php?script=sci_arttext\&pid=S1516-08582012000200007\&lng=pt.

4. Santos SR, Dias IMAV, Salimena AMO, Bara VMF. The existence of the parents of a child with congenital malformation. Rev. Min. Enferm. [Internet]. 2011 [cited 2019 Oct 11]; 15(4):491-7. Available from:

https://cdn.publisher.gn1.link/reme.org.br/pdf/v15n4a04.pdf.

5. Instituto Brasileiro de Geografia e Estatística (Br). Brasília (DF): IBGE; 2018. [cited 2019 Dec 16] Available from: https://www.ibge.gov.br/.

6. Departamento de Informática do SUS (Br). Brasília (DF): DATASUS; 2018. [cited 2019 agosto 09] Available from: https://tabnet.datasus.gov.br.

7. Bertaux, D. Narrativas de vida: a pesquisa e seus métodos, Natal-São Paulo: EDUFRN/Paulus, 2010.

8. Winnicott, W. A Criança e o seu Mundo. 6o Ed. Grupo Gen LTC editora. 1982.

9. Rosário SE, Penello LM. To understand the concept of facilitating environment and its use in the construction of public policies facilitating to the plenitude of life. Rev. Divulgação em saúde para debate [Internet]. 2016 [cited 2020 Oct 11]; 54:15-25. Available from: https://pesquisa.bvsalud.org/portal/resource/pt/biblio-996848.

10. Vicente SR, Paula KMP, Lopes AM, Muniz SA, Mancini CN, Trindade ZA. Emotional impact and maternal coping of congenital anomaly of babies in the NICU. Rev. Psicologia, Saúde \& Doenças [Internet]. 2016 [cited 2020 Nov 22]; 17(3):454467. DOI: https://doi.org/10.15309/16psd170312.

11. Silva LLT, Madeira AMF, Oliveira CG, Lima SCS, Campos TMF. Parents of babies malformados: an existential approach. Rev. Enferm. Cent. O. Min. [INTERNET]. 2016 [cited 2020 Mar 22]; 3(3):770-9. Available from: http://www.seer.ufsj.edu.br/index.php/recom/article/viewFile/408/523.

12. Heger AM, Silva DA, Pantoja MF. Pregnancy experience associated to fetal abnormality incompatible with life. Rev. Acta bioeth. [Internet]. 2018 [cited 2020 Nov 21]; 24(1):67-74. DOI: http://dx.doi.org/10.4067/S1726-569X2018000100067.

13. Souza ASR, Freitas SG. Humanization in fetal medicine. Rev. Bras. Saúde Mater [Internet]. Infant. 2018 [cited 2021 Apr 11]; 18(3):453-5. DOI: https://doi.org/10.1590/1806-93042018000300001.

14. Fernandes CR, Martins AC. Experiences and expectations of pregnant women in advanced maternal age with suspected or confirmed fetus malformation. Rev. REFACS (online). 2018 [cited 2021 Aug 11]; 6(3):416423. DOI: https://doi.org/10.18554/refacs.v6i3.3640.

15. Borges MM, Petean EBL. Fetal malformation: maternal coping, attachment and indicators of anxiety and depression. Revista da SPAGESP. 2018 [cited 2020 nov 11]; 19(2):137-48. Available from: http://pepsic.bvsalud.org/scielo.php?script=sci_arttext\&pid=S1677-29702018000200011.

16. Gonçalves TG, Xavier RB, Araújo LM, Arial LF. Nursery's contribution to the bonding process between mother and infant with inborn malformation. Rev. Pesq. Cuid. Fundam. [Internet]. 2011 [cited 2019 Sep 16]; 3(2):177690. Available from: http://www.seer.unirio.br/index.php/cuidadofundamental/article/view/1282/pdf_375. 
17. Alves SP, Bueno D. The profile of caregivers to pediatric patients with cystic fibrosis. Rev. Cien Saúde Colet. [Internet]. 2018 [cited 2020 Nov 20]; 23 (5):1451-7. DOI: https://doi.org/10.1590/1413-81232018235.18222016.

18. Fernandes IB, Xavier RB, São Bento PAS, Rodrigues A. On the way to interrupting the gestation or not: experiences of pregnant women with anencephalic fetuses. Rev. Ciênc. saúde coletiva. [Internet]. 2020 [cited 2021 Aug 10]; 25(2). DOI: https://doi.org/10.1590/1413-81232020252.14812018.

19. Moreira MCN, Nascimento MAF, Campos DS, Albernaz L, Costa ACC, Barros LBP, et al. Rare diseases and the associative dialogue: resignifications for moral experiences. Ciênc. saúde Colet. [Internet]. 2019 [cited 2020 Nov 22]; 24(10):36733682. DOI: https://doi.org/10.1590/1413-812320182410.11822019.

20. Diário oficial da República Federativa do Brasil. Lei 9263 de 12 de janeiro de 1996 (Br). Planejamento Familiar. Regula o § 70 do art. 226 da Constituição Federal, que trata do planejamento familiar, estabelece penalidades e dá outras providências. v. Diário Oficial da União - Seção 1 - 15/1/1996, Página 561. Brasília (DF): 1996 [cited 2019 Sep 16] Available from: http://www.planalto.gov.br.

21. Secretaria de Estado de Saúde do Rio de Janeiro (Br). Indicadores e informações em saúde. Rio de Janeiro (RJ): SESRJ; 2018. [cited 2019 Sep 16] Available from: https://www.saude.rj.gov.br/informacao-sus/dados-sus. 